\title{
Magneto-Dielectric Behaviour of M-Type Hexaferrite/Polymer Nanocomposites
}

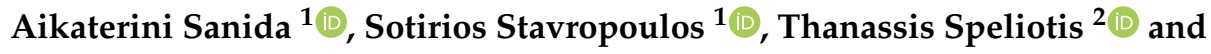 \\ Georgios C. Psarras 1,* \\ 1 Smart Materials \& Nanodielectrics Laboratory, Department of Materials Science, School of Natural Sciences, \\ University of Patras, 26504 Patras, Greece; ksanida@upatras.gr (A.S.); stavropoulos@upatras.gr (S.S.) \\ 2 Institute of Nanoscience and Nanotechnology, NCSR “Demokritos”, Aghia Paraskevi, 15310 Athens, Greece; \\ t.speliotis@inn.demokritos.gr \\ * Correspondence: G.C.Psarras@upatras.gr; Tel.: +30-261-096-9347
}

Received: 19 October 2018; Accepted: 11 December 2018; Published: 14 December 2018

\begin{abstract}
In the present study two sets of nanocomposites consisting of an epoxy resin and $\mathrm{BaFe}_{12} \mathrm{O}_{19}$ or $\mathrm{SrFe}_{12} \mathrm{O}_{19}$ nanoparticles were successfully developed and characterized morphologically and structurally via scanning electron microscopy and X-ray diffraction spectra. The dielectric response of the nanocomposites was investigated by means of broadband dielectric spectroscopy and their magnetic properties were derived from magnetization tests. Experimental data imply that the incorporation of the ceramic nanoparticles enhances significantly the dielectric properties of the examined systems and their ability to store electrical energy. Dielectric spectra of all systems revealed the presence of three distinct relaxation mechanisms, which are attributed both to the polymer matrix and the nanoinclusions: Interfacial polarization, glass to rubber transition of the polymer matrix and the re-orientation of small polar side groups of the polymer chain. The magnetic measurements confirmed the ferromagnetic nature of the nanocomposites. The induced magnetic properties increase with the inclusion of hexaferrite nanoparticles. The nanocomposites with $\mathrm{SrFe}_{12} \mathrm{O}_{19}$ nanoparticles exhibit higher values of coercive field, magnetization, magnetic saturation and remanence magnetization. A magnetic transition was detected in the ZFC/FC curves in the case of the $\mathrm{BaFe}_{12} \mathrm{O}_{19} /$ epoxy nanocomposites.
\end{abstract}

Keywords: barium ferrite; strontium ferrite; ferromagnetic nanocomposites; dielectric relaxations; magnetization; zero field cooled; field cooled; magnetic transition

\section{Introduction}

Ferrites belong in a large and well-established class of ceramic magnetic materials with a wide range of technological applications [1]. Ferrites are classified into two major types, the soft magnets characterized by domain walls which easily can be moved by an externally applied magnetic field and the hard magnets that are chemical compounds of metal oxides with strong magnetic properties, which are ideal for permanent magnets [2]. The M-type hexaferrites $\mathrm{MFe}_{12} \mathrm{O}_{19}(\mathrm{M}=\mathrm{Ba}$, $\mathrm{Sr}$ or $\mathrm{Pb})$ are important ferromagnetic oxides and have traditionally be used as permanent magnets in applications for dielectric media because of their high values of magneto-crystalline anisotropy and saturation magnetization. Because of their chemical stability, high intrinsic coercivity, large crystal anisotropy, high electrical resistivity, low cost, enhance resistance to the heat and high corrosion resistance, ferrites can be employed as components in a variety of microwave and high frequency electronic devices, used in magnetic recording media, communication, generation and distribution of electric energy, automotive and medical equipment [1-7]. Even though hexaferrites, have long been studied 
and become established materials, there are still several areas that are not completely defined and understood and new exciting properties are being discovered and opportunities are developed [6,8-10].

Polymers exhibit several advantages including easy processing and forming, thermomechanical stability, high dielectric breakdown strength and low cost. This is the main reason why many research efforts have focused on ceramic/polymer nanocomposites. Such composite materials can be moulded into complex shapes and they are suitable for adaptive devices where flexibility and elasticity are an additional and important parameter. Most studies to date have shown that polymer properties (such as mechanical, electrical, thermal, optical etc.) can be controlled by embedding suitable reinforcing nanoparticles [11,12]. Among others, ferrite nanoinclusions have been embedded in polymer matrix. Although the available studies are scarce and mostly concern physical and mechanical properties [13,14], it has been shown that a fine distribution of the magnetic filler in a polymer matrix influences significantly the conductivity, dielectric [13,15-18] and magnetic properties [19-21] of the systems, via the effective volume fraction of the nanoparticles. In the electronics industry, epoxy resins being excellent electrical insulators are the primary resin used in integrated circuits, transistors, hybrid circuits and printed circuit boards protecting electrical components from short circuiting, dust and moisture [22,23]. Additionally, flexible epoxy resins are used for potting transformers and inductors.

In this study, series of nanocomposites constituted of an epoxy resin acting as the matrix and two different hexaferrite nanoparticles $\left(\mathrm{BaFe}_{12} \mathrm{O}_{19}\right.$ and $\left.\mathrm{SrFe}_{12} \mathrm{O}_{19}\right)$ as the reinforcing phase, have been prepared and studied varying the filler content. Ferrites in their single crystal or ceramic form have been studied as monolithic materials $[9,24,25]$. In contrast, scarce attention has been given to ferrite/polymer nanocomposites [14,26] although ferrite nanoparticles could be beneficial to a bunch of composite properties including mechanical, electrical and magnetic performance. The quality of the developed systems was investigated via scanning electron microscopy (SEM) and X-ray diffraction (XRD) spectra, while dielectric and magnetic response were studied by means of broadband dielectric spectroscopy (BDS) and magnetization measurements employing a SQUID magnetometer, respectively.

\section{Materials and Methods}

Two different series of ferromagnetic nanocomposites were prepared using commercially available materials. In particular, a low viscosity epoxy resin (Epoxol $2004 \mathrm{~A}$ ) along with its curing agent (Epoxol $2004 \mathrm{~B}$ ), provided by Neotex S.A., Athens, Greece and $\mathrm{BaFe}_{12} \mathrm{O}_{19}, \mathrm{SrFe}_{12} \mathrm{O}_{19}$ nanoparticles, supplied by Sigma Aldrich (Saint Louis, MO, USA), were employed. The size of nanoparticles, according to the supplier's data sheet, is less than $100 \mathrm{~nm}$.

The specimens manufacturing procedure included mixing of the epoxy prepolymer and curing agent in a 2:1 $(w / w)$ ratio and the subsequent addition of various amounts of the ceramics nanopowder at room temperature, while stirring under ultrasonication for $10 \mathrm{~min}$, in order to achieve homogeneous filler dispersion and to avoid agglomeration. Afterwards mixtures were poured into silicon moulds for curing. Initial curing took place at ambient for seven days, followed by post-curing for four hours at $100{ }^{\circ} \mathrm{C}$. Manufactured specimens, were in the form of circular disk with diameter $36 \mathrm{~mm}$ and width $2 \mathrm{~mm}$ for dielectric measurements and in the form of cylinders with $6 \mathrm{~mm}$ and $5 \mathrm{~mm}$ diameter and height respectively for magnetic measurements. The filler concentration in the nanocomposites is expressed in parts per hundred resin per weight (phr).

The morphological characterization of the prepared samples was conducted by scanning electron microscopy (SEM) using an EVO MA-10 apparatus supplied by Carl Zeiss. For the structural investigation, $X$-ray diffraction (XRD) spectra were obtained via a Siemens diffractometer model Z500, by using Cu-Ka $(\lambda=1.54056 \AA, 40 \mathrm{kV}, 30 \mathrm{~mA})$ in a wide range of Bragg angles 20-90 ${ }^{\circ}$, for both the $\mathrm{BaFe}_{12} \mathrm{O}_{19}$ and $\mathrm{SrFe}_{12} \mathrm{O}_{19}$ nanopowders and the nanocomposites.

Dielectric characterization was carried out by means of broadband dielectric spectroscopy (BDS) in the frequency range of $10^{-1}-10^{7} \mathrm{~Hz}$ using an Alpha-N Frequency Response Analyzer and temperature interval from 30 to $160{ }^{\circ} \mathrm{C}$, with a temperature step of $10{ }^{\circ} \mathrm{C}$, controlled by Novotherm System. The specimens were placed inside the dielectric cell BDS 1200 which is a parallel plate capacitor 
with two gold-plated electrodes and the experimental data were obtained automatically via suitable software (Windeta), by performing isothermal frequency scans with the amplitude of the time varying voltage being equal to $1 \mathrm{~V}$ in all cases. The experimental equipment and the software were supplied by Novocontrol Technologies.

The magnetic characterization was conducted by employing a superconducting quantum interference device (SQUID) magnetometer, supplied by Quantum Design. The maximum applied magnetic field was $50 \mathrm{kOe}$. The zero-field-cooled (ZFC) and field cooled (FC) processes were recorded at low magnetic fields in temperature range from 5 to $300 \mathrm{~K}$. Prior of each run, specimens were demagnetized at $300 \mathrm{~K}$ by applying an oscillatory magnetic field and then cooled down in zero field to $5 \mathrm{~K}$. At $5 \mathrm{~K}$, a small magnetic field of the order of 100 or 1000 Oe was applied in the powder and the nanocomposites and the magnetization was measured as the sample was heated to $300 \mathrm{~K}$. This procedure was denoted as the ZFC measurement. At $300 \mathrm{~K}$, the small-applied magnetic field was kept as it is and then samples were cooled again to $2 \mathrm{~K}$, with a subsequent recording of the magnetization. Such measurement is denoted as FC measurement.

\section{Results}

\subsection{Morphological and Structural Characterization}

Figure 1 shows representative SEM images of the nanocomposites with $5 \mathrm{phr} \mathrm{BaFe}_{12} \mathrm{O}_{19}$ and $\mathrm{SrFe}_{12} \mathrm{O}_{19}$. The obtained SEM images revealed nanodispersions of the ceramic particles in the polymer matrix, while the formation of large aggregates or agglomerations has been avoided in both systems.

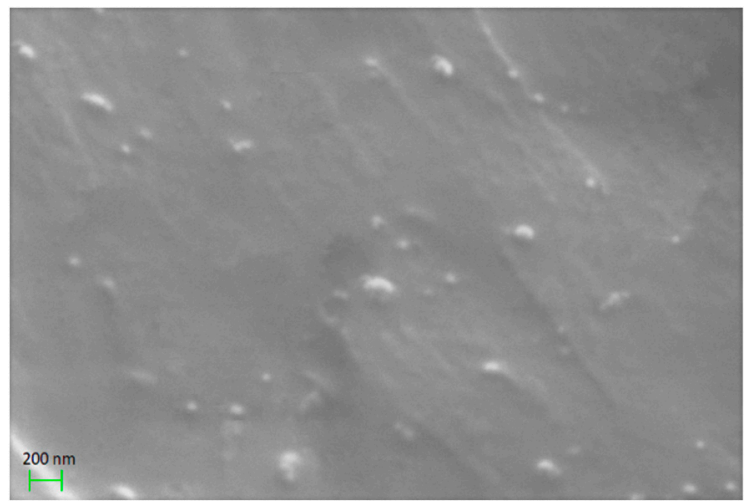

(a)

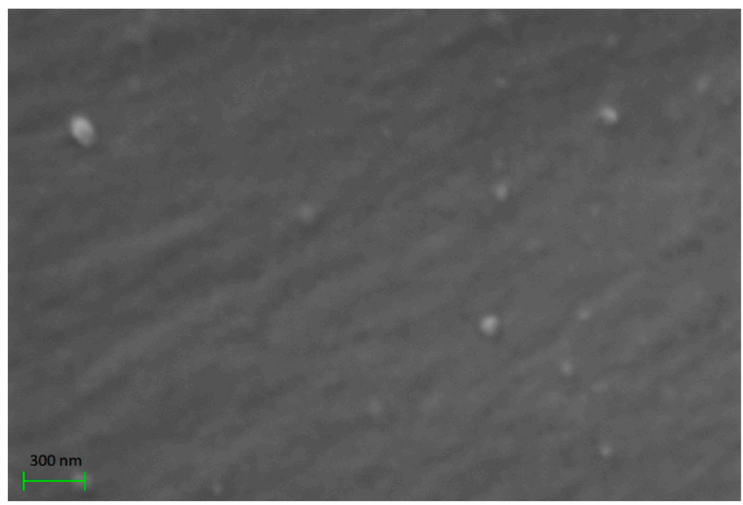

(b)

Figure 1. Scanning electron microscopy (SEM) images for the nanocomposites with 5 phr: (a) $\mathrm{BaFe}_{12} \mathrm{O}_{19}$; (b) $\mathrm{SrFe}_{12} \mathrm{O}_{19}$ content.

XRD patterns of the $\mathrm{BaFe}_{12} \mathrm{O}_{19}$ and $\mathrm{SrFe}_{12} \mathrm{O}_{19}$ nanopowders and their respective nanocomposites with $5 \mathrm{phr}$ filler content are illustrated in Figure 2. The diffraction peaks can be indexed to the typical magnetoplumbite-type (M-type) hexagonal structures of $\mathrm{BaFe}_{12} \mathrm{O}_{19}$ and $\mathrm{SrFe}_{12} \mathrm{O}_{19}$. XRD data revealed the coexistence of $\mathrm{Fe}_{2} \mathrm{O}_{3}$ [27] within both the $\mathrm{BaFe}_{12} \mathrm{O}_{19}$ nanoparticles and its respective nanocomposites, probably as a residue of the fabrication method of the ceramic nanopowder. In the $\mathrm{SrFe}_{12} \mathrm{O}_{19}$ nanopowder and the corresponding nanocomposites no characteristic peaks for other impurities have been observed.

\subsection{Dielectric Characterization}

The variation of the real part of dielectric permittivity as a function of frequency and temperature for the nanocomposites with $5 \mathrm{phr} \mathrm{BaFe}_{12} \mathrm{O}_{19}$ and $\mathrm{SrFe}_{12} \mathrm{O}_{19}$ concentration is presented in Figure $3 \mathrm{a}, \mathrm{b}$ respectively. The dielectric permittivity diminishes rapidly with frequency, because the permanent and induced dipoles do not have the necessary time to align themselves with the externally applied electric field. The $\varepsilon^{\prime}$ attains high values with increasing temperature since the thermal agitation 
facilitates the chain mobility thus enhancing the alignment of the chain dipoles, as well as the induced interfacial dipoles, with the field. The formation of a step like transition at intermediate frequencies and temperatures, known as $\alpha$-relaxation process, is a relaxation mechanism ascribed to the glass to rubber transition of the amorphous polymer matrix. This behaviour is representative for all examined systems independent of filler type and content.

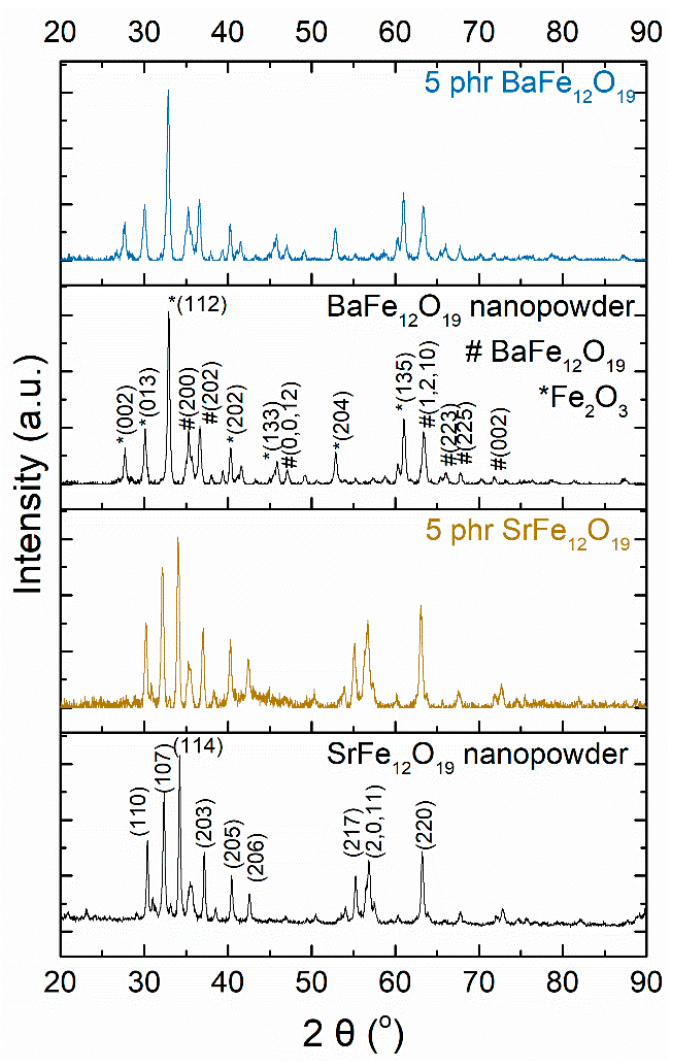

Figure 2. X-ray diffraction (XRD) spectra of the $\mathrm{BaFe}_{12} \mathrm{O}_{19}$ and $\mathrm{SrFe}_{12} \mathrm{O}_{19}$ nanopowders and their respective nanocomposites with $5 \mathrm{phr}$ filler content.

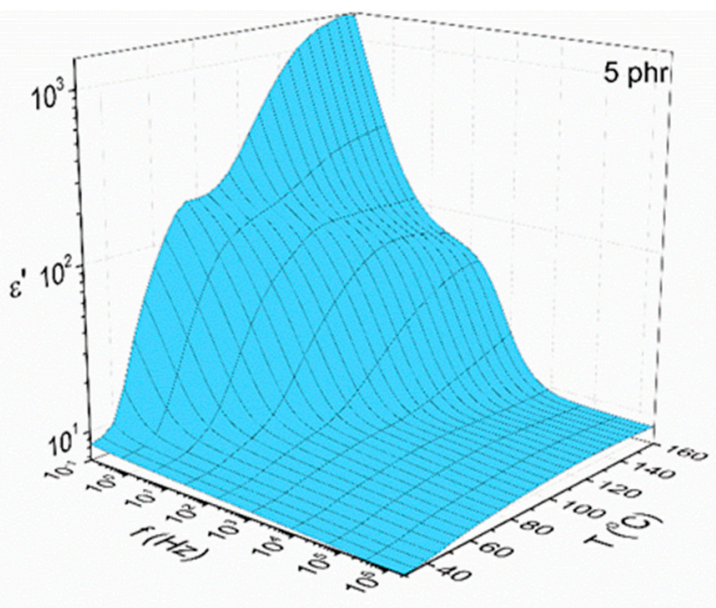

(a)

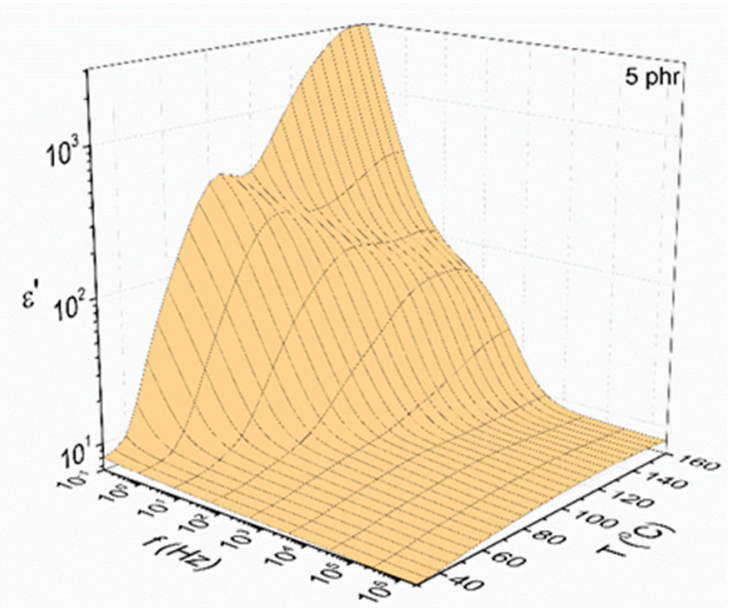

(b)

Figure 3. The variation of the real part of dielectric permittivity as a function of frequency and temperature for the nanocomposites with 5 phr: (a) $\mathrm{BaFe}_{12} \mathrm{O}_{19}$; (b) $\mathrm{SrFe}_{12} \mathrm{O}_{19}$ filler content.

Three distinct relaxation mechanisms were identified in the spectra of all examined systems as shown in Figure 4, which depicts the variation of the loss tangent versus frequency and temperature. 
The presence of relaxation processes becomes evident by the formation of loss peaks in the spectra of loss tangent. The faster and also weaker relaxation mechanism, appearing at high frequencies, is attributed to the reorientation of small polar side groups of the polymer chain ( $\beta$-relaxation). At intermediate frequencies and temperatures, $\alpha$-relaxation is recorded which is related to the transition of the polymer matrix from the glassy to rubbery state. This mechanism reflects the synergetic segmental motion of the polymer chain. Finally, at the low frequencies and high temperatures the formation of a peak is an indication of interfacial polarization (IP) or Maxwell-Wagner-Sillars (MWS) effect, which is related to the heterogeneity of the examined systems and results from the accumulation of unbounded charges at the interface between the matrix and the nanoinclusions.

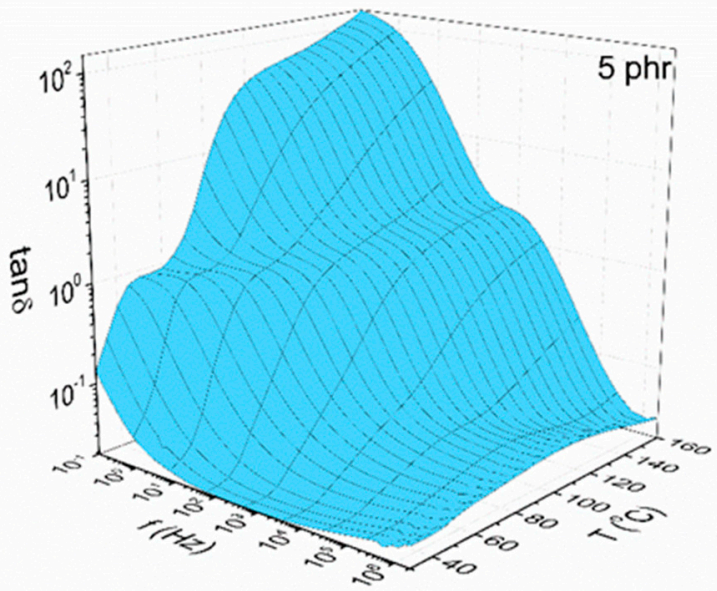

(a)

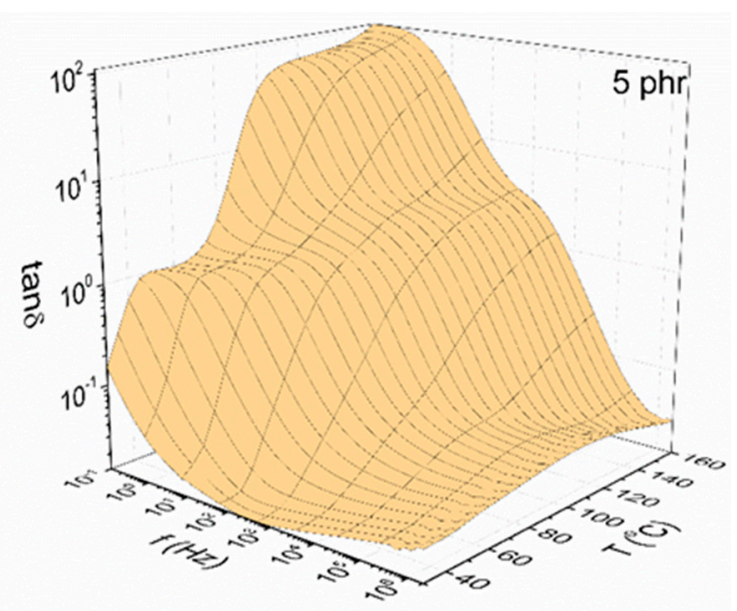

(b)

Figure 4. The variation of the loss tangent as a function of frequency and temperature for the nanocomposites with 5 phr: (a) $\mathrm{BaFe}_{12} \mathrm{O}_{19}$; (b) $\mathrm{SrFe}_{12} \mathrm{O}_{19}$ filler content.

\section{Discussion}

Figure 5 displays comparative plots of the real part of the dielectric permittivity $\left(\varepsilon^{\prime}\right)$ with frequency, at $30{ }^{\circ} \mathrm{C}$, for the (a) $\mathrm{BaFe}_{12} \mathrm{O}_{19}$ and (b) $\mathrm{SrFe}_{12} \mathrm{O}_{19}$ systems respectively. As expected, $\varepsilon^{\prime}$ increases systematically with filler content in the whole frequency range, since both barium ferrite and strontium ferrite nanoparticles exhibit higher values of permittivity and conductivity than the polymer matrix. In the low frequency region, the influence of interfacial polarization due to the increasing heterogeneity of the system with filler content makes this increase more pronounced. Systems filled with barium ferrite seem to exhibit slightly higher values than those with strontium ferrite at constant filler content, in this low temperature region.

Comparative plots of the loss tangent, as a function of frequency, for the $\mathrm{SrFe}_{12} \mathrm{O}_{19}$ system, at $160{ }^{\circ} \mathrm{C}$ is presented in Figure 6. It should be noted that the barium ferrite filled systems exhibit a similar behaviour. The previously mentioned relaxations are present in these loss spectra of all studied systems. Since loss tangent is defined as the ratio of the imaginary to the real part of dielectric permittivity variations of loss tangent with filler content, in the low frequency range, should be related to interfacial polarization phenomena. Values of loss tangent diminish with barium ferrite content, reflecting the increase of polarization and thus of $\varepsilon^{\prime}$, due to the enhanced heterogeneity. Interestingly, IP is observed also in the neat epoxy spectrum. IP has been detected in the loss spectra of many polymers due to the presence of additives, impurities and plasticizers. The inset diagram of Figure 6 depicts the comparative loss tangent spectra as a function of frequency at $160{ }^{\circ} \mathrm{C}$ for the 5 phr and $15 \mathrm{phr}$ filler content of both examined systems. Barium ferrite systems exhibit higher values than the $\mathrm{SrFe}_{12} \mathrm{O}_{19}$ nanocomposites indicating that the increasing rate of the real part of permittivity is higher than the corresponding rate of the losses for the strontium ferrite filled systems. Also, the IP peaks of 
the strontium ferrite nanocomposites shift to higher frequencies than the barium ferrite ones indicating the facilitation of the process.

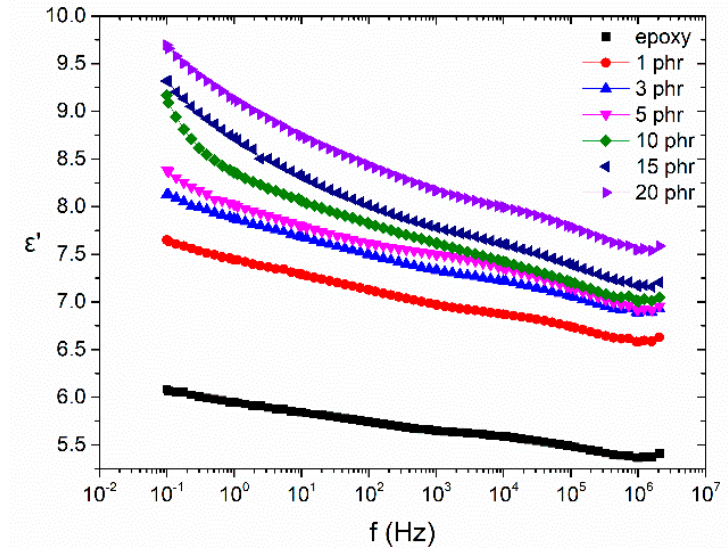

(a)

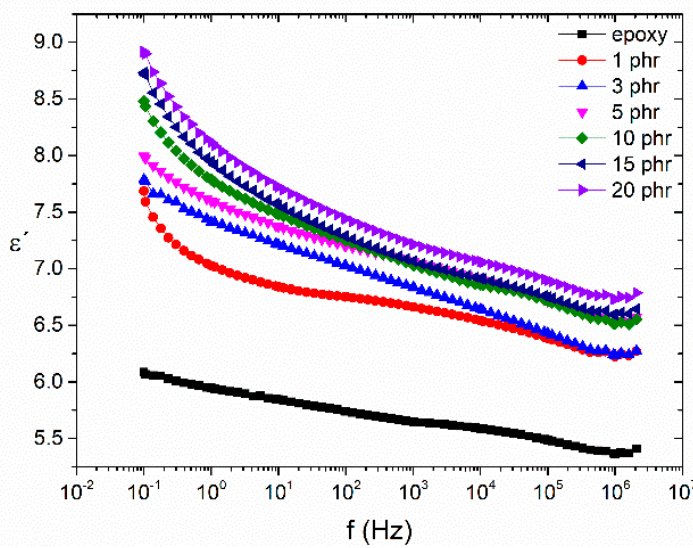

(b)

Figure 5. Real part of dielectric permittivity as a function of frequency, at $30{ }^{\circ} \mathrm{C}$, for the nanocomposites with: (a) $\mathrm{BaFe}_{12} \mathrm{O}_{19}$; (b) $\mathrm{SrFe}_{12} \mathrm{O}_{19}$ nanoparticles.

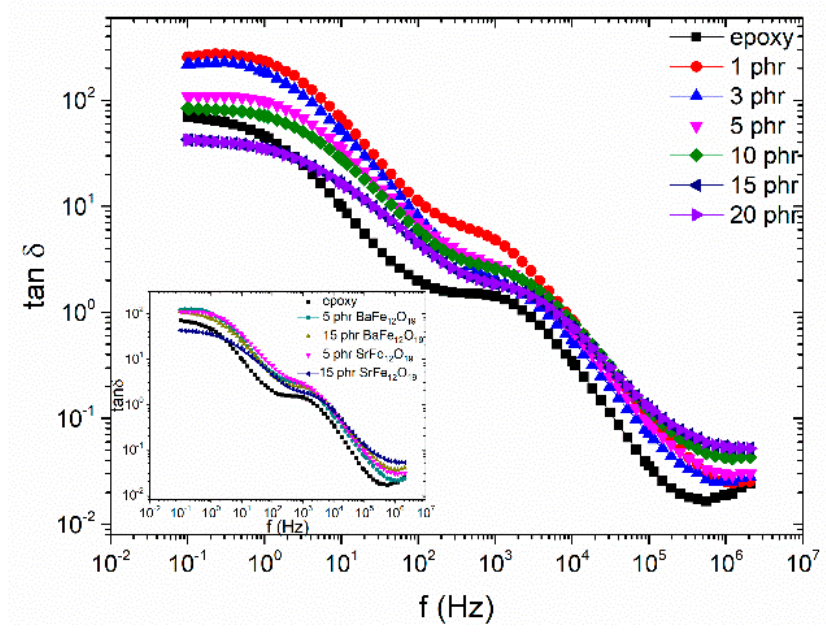

Figure 6. Loss tangent as a function of frequency, for $\mathrm{SrFe}_{12} \mathrm{O}_{19}$ examined systems, at $160{ }^{\circ} \mathrm{C}$. Inset depicts the comparative loss tangent spectra, as a function of frequency, at $160{ }^{\circ} \mathrm{C}$ for the $5 \mathrm{phr}$ and 15 phr filler content of $\mathrm{SrFe}_{12} \mathrm{O}_{19}$ and $\mathrm{BaFe}_{12} \mathrm{O}_{19}$ systems.

Figure 7 presents a comparison of the Dielectric Reinforcing Function (DRF) as a function of temperature at $0.1 \mathrm{~Hz}$ for the two different fillers $\left(\mathrm{BaFe}_{12} \mathrm{O}_{19}\right.$ and $\left.\mathrm{SrFe}_{12} \mathrm{O}_{19}\right)$ at the same concentration (5 phr and 15 phr). DRF is defined according to Equation (1):

$$
G(f, T)=\frac{\varepsilon_{\text {comp }}^{\prime}(f, T)}{\varepsilon_{\text {matrix }}^{\prime}(f, T)}
$$

where $\varepsilon_{\text {comp }}^{\prime}(f, T)$ and $\varepsilon_{\text {matrix }}^{\prime}(f, T)$ is the real part of dielectric permittivity of the composite and the matrix respectively, while $f$ is the frequency of the field and $T$ the temperature. DRF is a dimensionless function being a measure of the normalized polarization, upon the geometrical characteristics of the samples, reflecting also the dielectric strengthening ability of the inclusions. So, DRF offers a strong indication relative to the energy storing efficiency of the composites [28]. The strontium ferrite systems seem to have the capability of storing more energy than the barium ferrite filled nanocomposites, even at lower filler content, in the greater part of the temperature range; reaching up to nine times the energy stored in the neat epoxy for the 15 phr specimen, at the maximum point of the function, 
comparing to just four times for the barium ferrite system with the same concentration. The peak formed at high temperatures is assigned to interfacial polarization because of the accumulation of unbounded charges at the interface between the filler and the polymer matrix. The shape of the peak suggests the overlapping of two or more interfacial polarization processes with different relaxation times due to the distribution of the geometrical size of the formed dipoles [16]. Microscopic results via SEM from a previous study [16] has shown the existence of two groups with different nanoinclusion sizes in the examined strontium ferrite nanocomposites. The peaks appearing as fluctuations at lower temperatures express the different dynamics of the $\alpha$ - and $\beta$-relaxation between the polymer matrix and the nanocomposites.

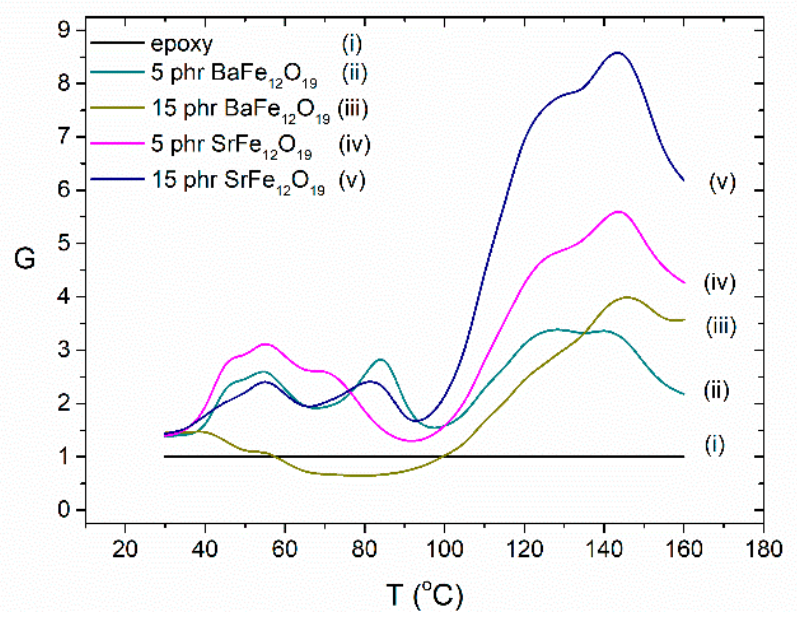

Figure 7. Dielectric Reinforcing Function (DRF) as a function of temperature at $0.1 \mathrm{~Hz}$, for the nanocomposites with $5 \mathrm{phr}$ and $15 \mathrm{phr} \mathrm{BaFe}_{12} \mathrm{O}_{19}$ and $\mathrm{SrFe}_{12} \mathrm{O}_{19}$ content.

The relaxation dynamics or else the dependence of the loss peak frequency upon temperature for the IP and $\alpha$-relaxation mechanisms for the nanocomposites with (a) $\mathrm{BaFe}_{12} \mathrm{O}_{19}$ and (b) $\mathrm{SrFe}_{12} \mathrm{O}_{19}$ nanoparticles is presented in Figure 8. The IP process for the barium ferrite filled systems as well as the $\beta$-relaxation for both examined systems, gave a limited number of loss peaks. For this reason, a reliable fitting procedure could not be performed and therefore they are missing from the study of relaxation dynamics. IP follows an Arrhenius type dependence on temperature given by Equation (2):

$$
f_{\max }=f_{0} e^{-\frac{E_{A}}{k_{B} T}}
$$

where $f_{\max }$ is the loss peak frequency, $f_{0}$ a pre-exponential factor, $E_{A}$ the activation energy of the recorded process, $T$ the temperature and $k_{B}$ the Boltzmann's constant. The temperature dependence of the loss peak position for the glass to rubber transition process ( $\alpha$-relaxation) is described by the VFTH (Vogel-Fulcher-Tammann-Hesse) relation, expressed via Equation (3):

$$
f_{\max }=f_{0} e^{-\frac{A}{\left(T-T_{0}\right)}}
$$

where $f_{0}$ is a pre-exponential factor, $A$ is a measure of the activation energy of the mechanism and $T_{0}$ the Vogel temperature or ideal glass transition temperature, being lower than the experimentally determined value of $T_{g}$. All fitting parameters are listed in Table 1. Dielectric data can be also be employed for the estimation of the glass transition temperature via the convention that $\tau\left(T_{g, d i e l}\right)=100 \mathrm{~s}$, which relates the relaxation time $(\tau)$ of $\alpha$-relaxation with $T_{g}$ [29]. Extrapolating the VFTH curves of Figure 8 to the peak frequency, which corresponds to $\tau=100 \mathrm{~s}$, allows to determine of the $T_{g, \text { diel }}$ values listed in Table 1 . 


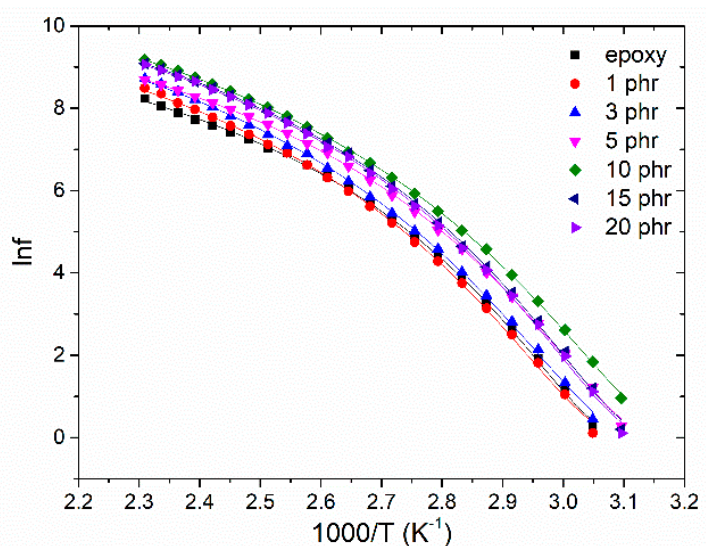

(a)

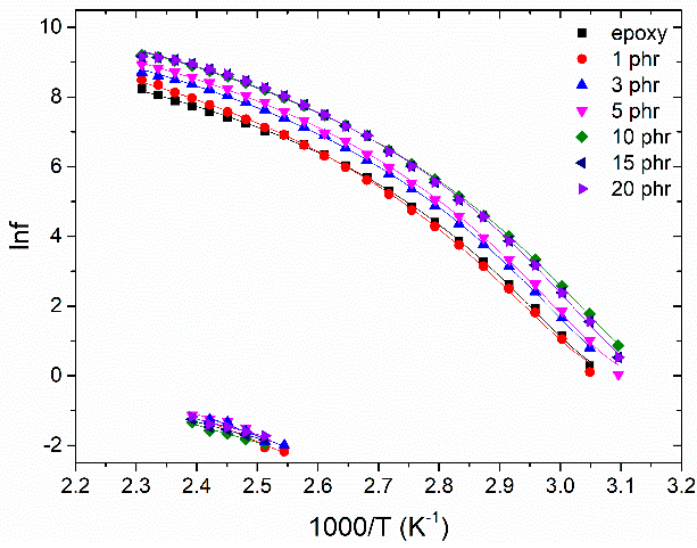

(b)

Figure 8. Temperature dependence of the loss peak position for the IP and $\alpha$-relaxation mechanisms for the nanocomposites with: (a) $\mathrm{BaFe}_{12} \mathrm{O}_{19}$; (b) $\mathrm{SrFe}_{12} \mathrm{O}_{19}$ nanoparticles.

Table 1. Specimens' composition in phr, activation energy values and parameters derived via fitting data with Equations (2) and (3), for all studied systems and glass transition temperature as determined via BDS.

\begin{tabular}{|c|c|c|c|c|c|c|c|}
\hline \multirow{3}{*}{ Specimens } & \multicolumn{3}{|c|}{$\mathrm{BaFe}_{12} \mathrm{O}_{19}$} & \multicolumn{4}{|c|}{$\mathrm{SrFe}_{12} \mathrm{O}_{19}$} \\
\hline & \multicolumn{2}{|c|}{$\alpha$-Relaxation } & \multirow{2}{*}{$T_{g}$, dielectric $(\mathrm{K})$} & \multicolumn{2}{|c|}{$\alpha$-Relaxation } & \multirow{2}{*}{$\frac{\text { IP }}{E_{A}(\mathrm{eV})}$} & \multirow{2}{*}{$T_{g, \text { dielectric }}(\mathbf{K})$} \\
\hline & $A(\mathrm{~K})$ & $T_{0}(\mathrm{~K})$ & & $A(\mathrm{~K})$ & $T_{0}(\mathrm{~K})$ & & \\
\hline Epoxy & 17.5 & 315.9 & 320.9 & 17.5 & 315.9 & & 320.9 \\
\hline $1 \mathrm{phr}$ & 19.9 & 314.9 & 320.7 & 19.3 & 314.7 & 0.624 & 320.2 \\
\hline $3 \mathrm{phr}$ & 20.5 & 312.3 & 318.1 & 18.6 & 312.1 & 0.571 & 317.4 \\
\hline $5 \mathrm{phr}$ & 18.1 & 310.3 & 315.4 & 18.3 & 311.7 & 0.526 & 316.9 \\
\hline $10 \mathrm{phr}$ & 20.1 & 304.7 & 310.3 & 18.3 & 307.1 & 0.427 & 312.3 \\
\hline $15 \mathrm{phr}$ & 18.3 & 310.5 & 315.7 & 17.4 & 309.6 & 0.399 & 314.5 \\
\hline $20 \mathrm{phr}$ & 18.4 & 311.0 & 316.2 & 17.4 & 309.6 & 0.376 & 314.5 \\
\hline
\end{tabular}

From the fitted parameters, apparently, all nanocomposites exhibit lower $T_{0}$ and $T_{g, \text { diel }}$ values than the neat epoxy indicating indirectly strong interactions between the nanoparticles. The addition of nanoinclusions modifies the extend of crosslinking in the polymer system's network, thus increasing the free volume and enhancing the chain flexibility which ultimately results in an increase of the systems' polarization [30]. At the two higher filler contents, relaxation dynamics show an increase in the $T_{0}$ and $T_{g, \text { diel }}$ values indicating strong adhesion of the filler to the matrix. The excess number of nanoparticles exerts spatial restrictions to macromolecules and allows the occurrence of strong attractive interactions, not only between the nanoparticles but also between nanoparticles and the polymer matrix, obstructing thus the cooperative segmental mobility of the polymer chains [16,31].

The activation energy of the IP process for the $\mathrm{SrFe}_{12} \mathrm{O}_{19}$ filled systems is listed in Table 1. Once again it should be noted that the analysis for the $\mathrm{BaFe}_{12} \mathrm{O}_{19}$ systems is omitted because of the limited number of peaks available for a reliable fitting. The activation energy values diminish with filler content since the increasing heterogeneity of the systems facilitates the occurrence of the IP process. The monotonous decrease of the $E_{A}$ values is also a sign for the fine dispersion of the nanofiller into the matrix. The formation of isolated particles' clusters, due to agglomeration, could act as charge traps or conductive paths dead ends resulting in enhanced inertia of the dipoles at the interfaces and thus in higher relaxation times. Consequently, activation of the IP mechanism should require increased thermal agitation leading to higher values of activation energy.

Figure $9 \mathrm{a}, \mathrm{b}$ present the magnetic hysteresis loops, as recorded at room temperature, for polymer nanocomposites filled with $\mathrm{BaFe}_{12} \mathrm{O}_{19}$ and $\mathrm{SrFe}_{12} \mathrm{O}_{19}$ nanoparticles respectively. Each inset depicts the hysteresis loops of the respective nanopowder. The hysteresis loops confirm the ferromagnetic 
behaviour of nanocomposites, which is attributed to the magnetic nanoparticle content. Magnetization of the nanocomposites increases with the magnetic phase content since both barium ferrite and strontium ferrite nanoparticles induce magnetic properties into the polymer matrix. Obviously, the magnetization values of both nanocomposite systems are lower with respect to the corresponding ones of the ceramic nanopowders, due to their low filler content and the presence of the nonmagnetic polymer matrix. Coercivity values remain nearly constant for all the samples of each examined series, indicating that the coercive behaviour is controlled by the type of nanoparticles in accordance to the typical particle-loading-independent coercivity response. The coercive field, as an intrinsic property of the nanoparticles, detains the same value of $1.3 \mathrm{kOe}$ for $\mathrm{BaFe}_{12} \mathrm{O}_{19}$ and $4 \mathrm{kOe}$ for $\mathrm{SrFe}_{12} \mathrm{O}_{19}$ nanopowders, as well as for their respective nanocomposites. The overall shape of the hysteresis loop and the lower coercive field recorded for the $\mathrm{BaFe}_{12} \mathrm{O}_{19}$ nanopowder are attributed to the coexistence with the $\mathrm{Fe}_{2} \mathrm{O}_{3}$ phase detected in the X-ray diffraction spectra.

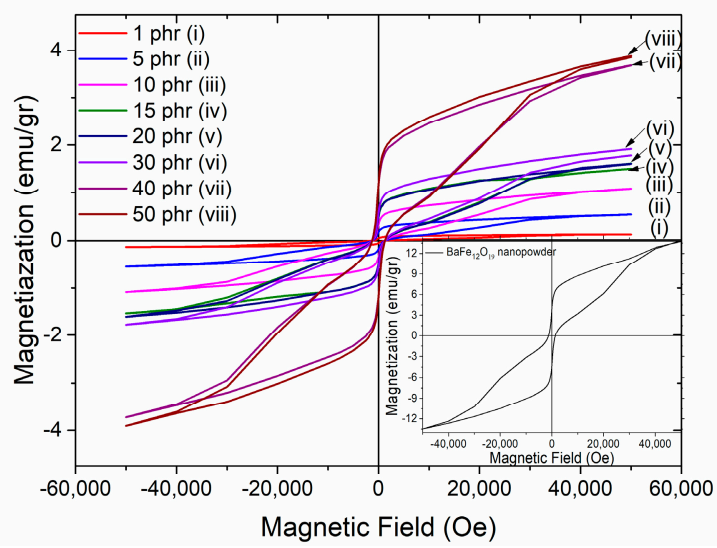

(a)

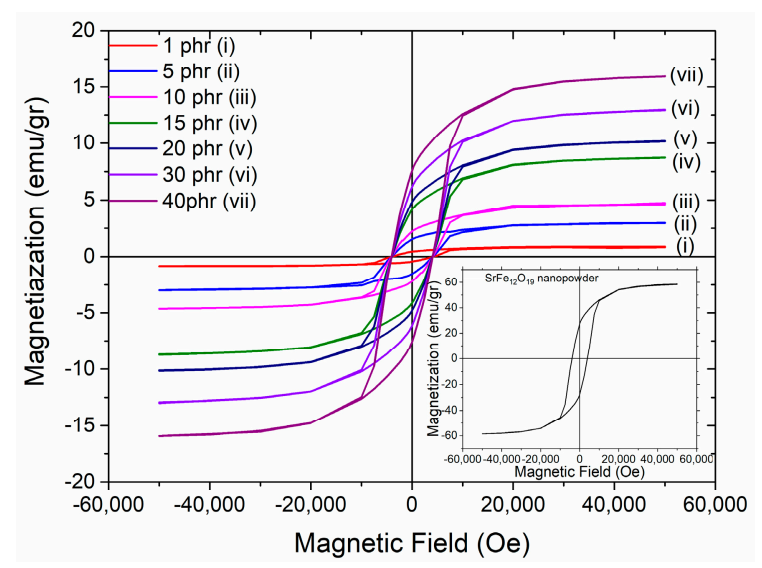

(b)

Figure 9. Magnetic hysteresis loops for the nanocomposites with varying: (a) $\mathrm{BaFe}_{12} \mathrm{O}_{19}$; (b) $\mathrm{SrFe}_{12} \mathrm{O}_{19}$ filler content. Insets depict the hysteresis loops of their respective nanopowders.

The variation of magnetization as a function of the magnetic filler concentration for the nanocomposites with (a) $\mathrm{BaFe}_{12} \mathrm{O}_{19}$ and (b) $\mathrm{SrFe}_{12} \mathrm{O}_{19}$ nanoparticles, determined from the hysteresis loops of Figure 9 is shown in Figure 10a,b respectively. Both the magnetic saturation $\left(M_{s}\right)$ and magnetic remanence $\left(M_{r}\right)$ of the nanocomposites increase with magnetic filler content, since the magnetic properties are induced in the nanocomposites by the included nanoparticles. The $M_{S}$ values of $\mathrm{SrFe}_{12} \mathrm{O}_{19}$ nanocomposites are approximately four times higher than those of the $\mathrm{BaFe}_{12} \mathrm{O}_{19}$ systems, while the $M_{r}$ values of the $\mathrm{SrFe}_{12} \mathrm{O}_{19}$ nanocomposites are even higher, approximating seven times as indicated by the slope of the linear fitting. The latter expresses the rate of increasing magnetization with filler content for each system. The observed linear increase in the values of saturation magnetization and magnetic remanence can be attributed to the fine dispersion of the magnetic nanoparticles in the polymer matrix.

The low temperature magnetic properties are further elucidated through ZFC and FC magnetic measurement of the samples. Figure 11 presents the ZFC and FC magnetization measurements for the (a) $\mathrm{BaFe}_{12} \mathrm{O}_{19}$ and (b) $\mathrm{SrFe}_{12} \mathrm{O}_{19}$ nanoparticles, measured under a magnetic field of 1000 Oe. Figure 11 shows the ZFC and FC magnetization measurements for the nanocomposites with 5 and 40 phr content in (a) $\mathrm{BaFe}_{12} \mathrm{O}_{19}$ and (b) $\mathrm{SrFe}_{12} \mathrm{O}_{19}$, measured under a field of 100 Oe. The FC magnetization curve is always above the ZFC curve up to room temperature. The irreversibility temperature $\left(T_{\text {irr }}\right)$ or else the temperature where the ZFC splits from the FC curve, is at $300 \mathrm{~K}$ for both the nanocomposite systems and their respective nanopowder, which is characteristic for non-interacting magnetic particles. 


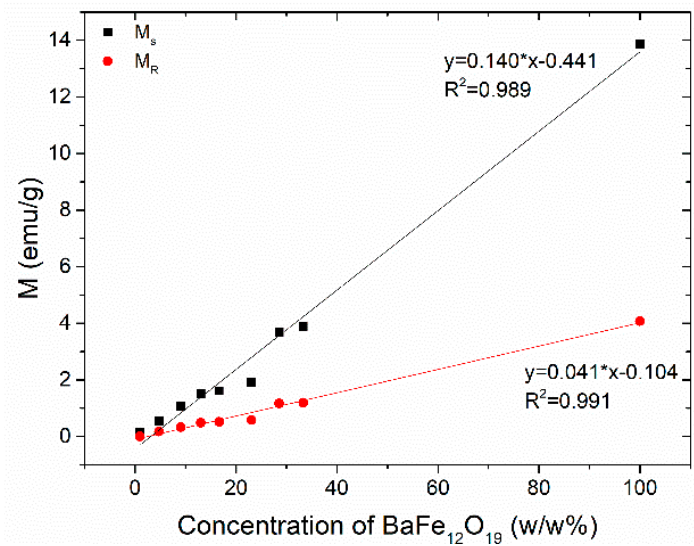

(a)

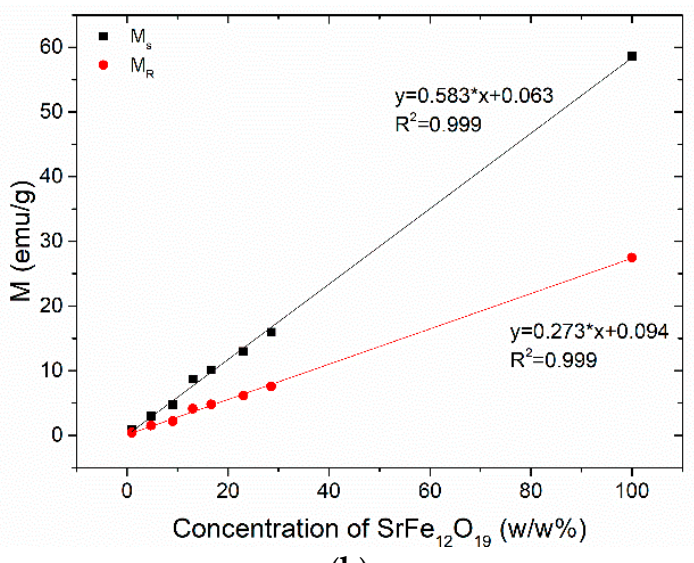

(b)

Figure 10. The variation of magnetization as a function of the magnetic filler concentration for the nanocomposites with: (a) $\mathrm{BaFe}_{12} \mathrm{O}_{19}$; (b) $\mathrm{SrFe}_{12} \mathrm{O}_{19}$ nanoparticles.

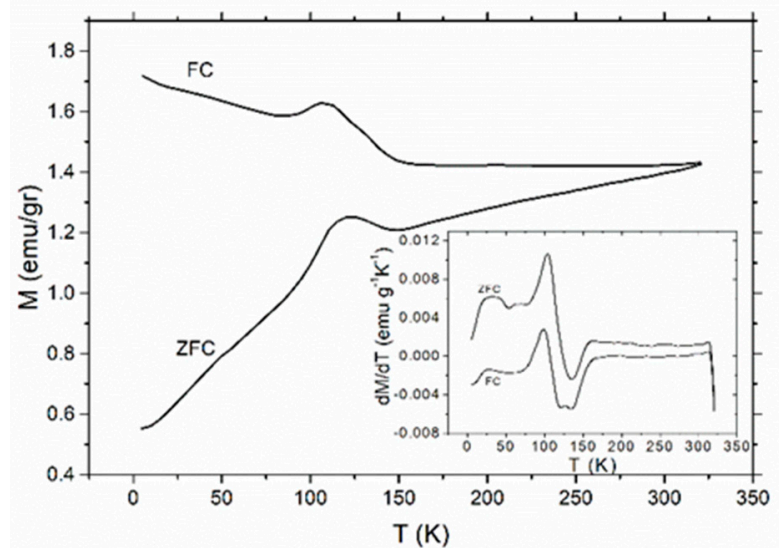

(a)

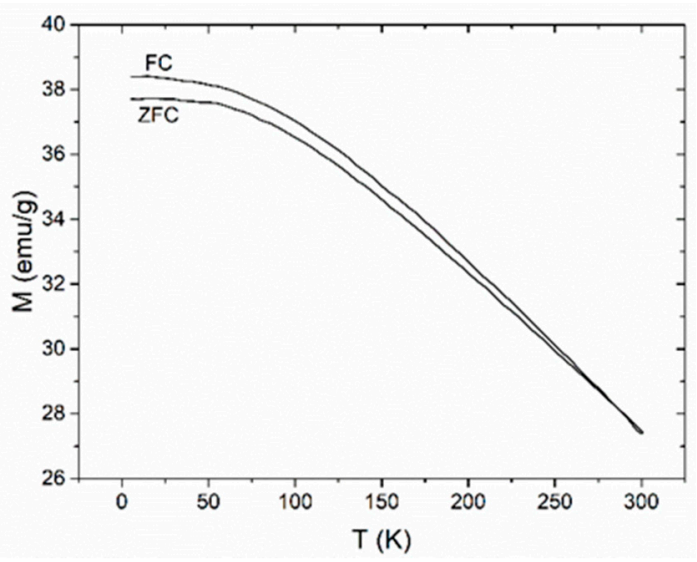

(b)

Figure 11. The zero-field cooled (ZFC) and field cooled (FC) magnetization curves for: (a) $\mathrm{BaFe}_{12} \mathrm{O}_{19}$; (b) $\mathrm{SrFe}_{12} \mathrm{O}_{19}$ nanopowders. Inset in (a) depicts the 1st derivative of ZFC and FC magnetization curves versus temperature for the $\mathrm{BaFe}_{12} \mathrm{O}_{19}$ nanopowder.

The ZFC curve of barium ferrite and its nanocomposites increases with temperature forming a peak approximately at $110 \mathrm{~K}$, which is followed by a slow increase of magnetization up to $300 \mathrm{~K}$. This behaviour signifies a magnetic transition. In order to further investigate this behaviour the first derivative of ZFC and FC curves has been calculated for the barium ferrite systems. Representative plots are depicted as insets in Figures 11a and 12a. Peak's position was found to be at $109 \mathrm{~K}$ in all nanocomposites with barium ferrite and at $105 \mathrm{~K}$ for the neat nanopowder. This small difference could be assigned to the stronger employed field for the nanopowder measurement. Moreover, peaks in FC curves seem to slightly shift to lower temperatures. Recorded transition cannot be easily interpreted and attributed undoubtedly to a specific physical mechanism. The simultaneous presence of barium ferrite and iron oxide in the reinforcing nanopowder necessitates examining both ingredients as the possible origin of the transition. The peak of the detected transition appears at a temperature closed to the Verwey transition (occurring at $T_{V} \sim 120 \mathrm{~K}$ ) of $\mathrm{Fe}_{3} \mathrm{O}_{4}$, which is a first order magnetic phase transition related to the change of magnetocrystalline anisotropy and ordering of $\mathrm{Fe}^{3+}$ and $\mathrm{Fe}^{2+}$ ions at the octahedral sites of cubic spinel structure. Verwey transition is considered as characteristic of a pure, nearly stoichiometric population of magnetite. Under oxidative conditions magnetite transforms gradually to its oxidized form of maghemite $\left(\gamma-\mathrm{Fe}_{2} \mathrm{O}_{3}\right)$. In the literature there are studies reporting that the presence of non-stoichiometric maghemite induces a decrease in Verwey temperature [32-34]. Other studies about polycrystalline Ba hexaferrites and $\mathrm{BaO}^{*} \mathrm{nFe}_{2} \mathrm{O}_{3}$ of slightly deviating stoichiometry, 
have also indicated the occurrence of this process with decreasing $T_{v}$ temperature [35-37]. On the other hand, the polymorphism of iron oxides and the low magnetization values of $\mathrm{BaO}^{*} 6 \mathrm{Fe}_{2} \mathrm{O}_{3}$ in tandem with its difficulty to reach saturation (inset of Figure 9a) suggests another interpretation by considering that the present iron oxide could be, at least partially, in the form of $\alpha-\mathrm{Fe}_{2} \mathrm{O}_{3}$ (hematite) or $\varepsilon-\mathrm{Fe}_{2} \mathrm{O}_{3}$. In the case of $\alpha-\mathrm{Fe}_{2} \mathrm{O}_{3}$, in its bulk form, a magnetic transition from the weak ferromagnetic phase to antiferromagnetic one occurs at $260 \mathrm{~K}$, known as Morin temperature $\left(T_{M}\right)$. Morin temperature appears to be sensitive on particle shape, size, crystallinity and in general decreases with particle size, vanishing for spheroids with diameter below $10 \mathrm{~nm}$ [38-40]. Furthermore, the $\varepsilon-\mathrm{Fe}_{2} \mathrm{O}_{3}$ polymorph of ferric oxide exhibits a magnetic transition at approximately $110 \mathrm{~K} \cdot \varepsilon-\mathrm{Fe}_{2} \mathrm{O}_{3}$ exists only in nanoscale and transforms to hematite upon increasing its dimensions and by heating [41-44]. Unconfined $\varepsilon-\mathrm{Fe}_{2} \mathrm{O}_{3}$ nanoparticles transform to hematite at temperatures ranging between 700 and $1300 \mathrm{~K}$ [41]. At $110 \mathrm{~K}$ $\varepsilon-\mathrm{Fe}_{2} \mathrm{O}_{3}$ undergoes a transition from a magnetic ordered state to another magnetic status. A dispute for the physical origin of this transition is present in the literature. The first approach considers a magnetic transition from a collinear ferromagnetic state to an incommensurate magnetic structure (probably of a square-wave-modulated origin). The second one, considers the transition from a canted antiferromagnetic state (characterized by a specific canting angle) to another canted antiferromagnetic state (characterized by a different canting angle). The latter resembles to a Morin-like transition [41-43].

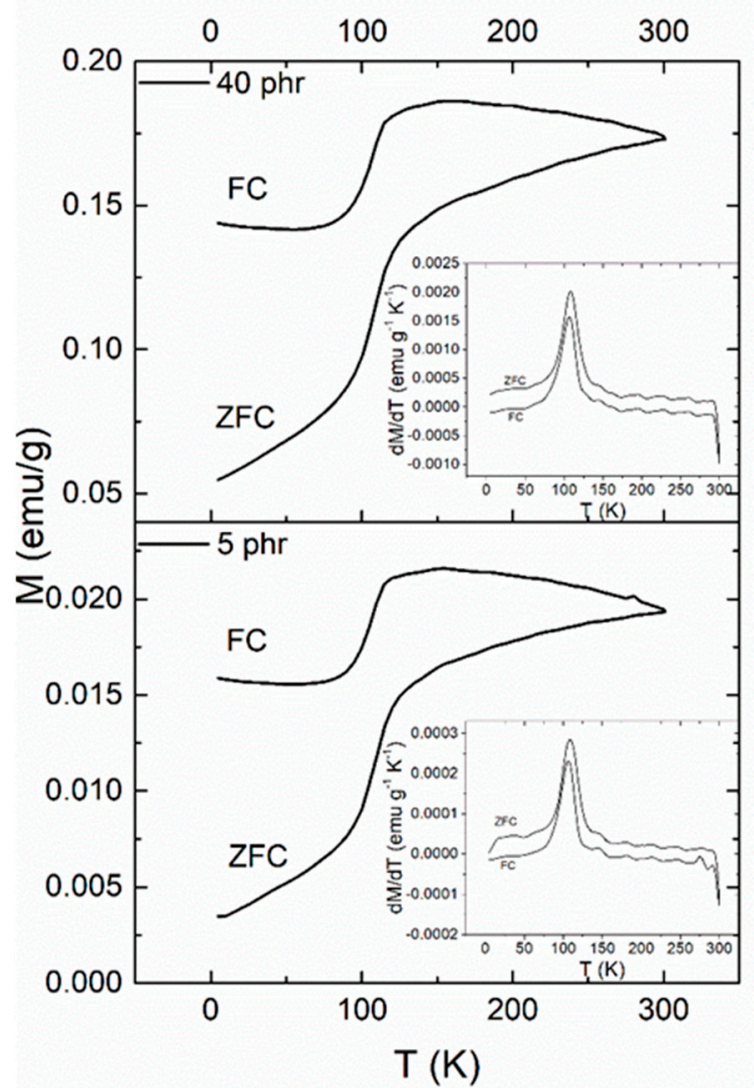

(a)

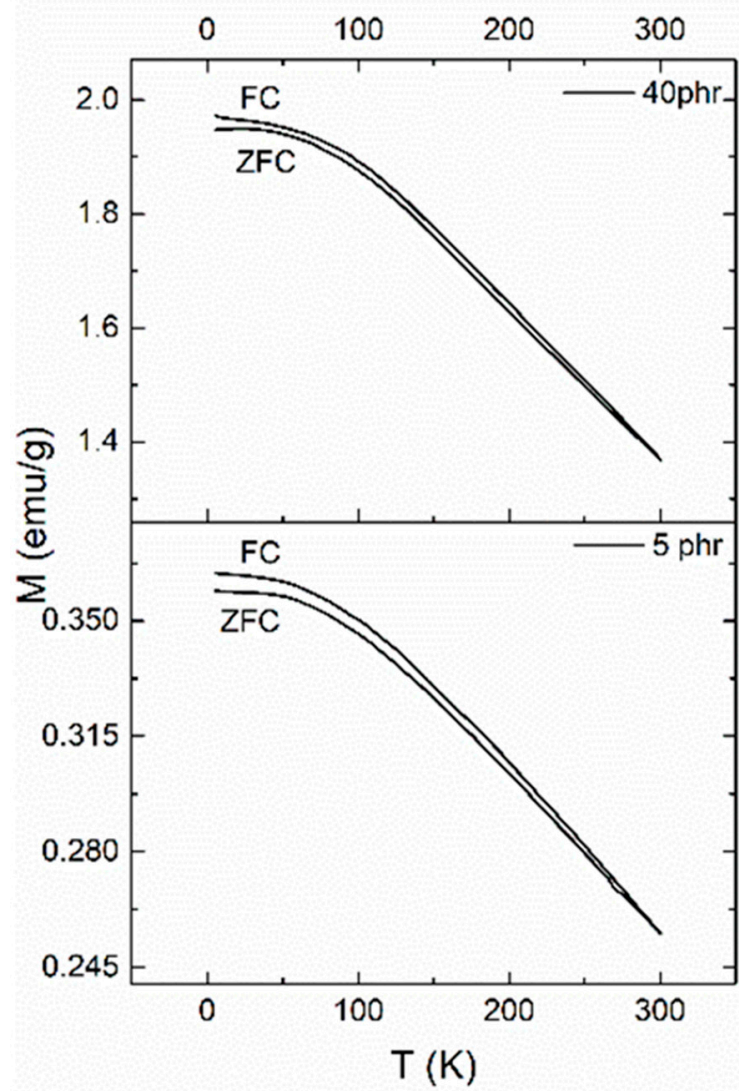

(b)

Figure 12. The ZFC and FC magnetization curves for the 5 and 40 phr nanocomposites with: (a) $\mathrm{BaFe}_{12} \mathrm{O}_{19}$; (b) $\mathrm{SrFe}_{12} \mathrm{O}_{19}$ filler content. Inset in (a) depicts the 1st derivative of the ZFC and FC magnetization curves versus temperature for the 5 and $40 \mathrm{phr} \mathrm{BaFe}_{12} \mathrm{O}_{19}$ nanocomposites.

In order to elucidate the possible origin of the recorded transition in Figures 11a and 12a a detailed analysis of the relative XRD spectra was carried out. For this reason, suitable software was employed (Match! Crystal Impact, Bonn, Germany). Results indicate the presence of at least two phases. The first one has an hexagonal crystal system with the $P 6_{3} / m m c$ space group and lattice parameters $a=5.8000 \AA$ 
and $c=23.1800 \AA$ and is attributed to $\mathrm{BaFe}_{12} \mathrm{O}_{19}$, while the second one has an orthorhombic crystal system with the Pna2 ${ }_{1}$ space group and lattice parameters $a=5.0850 \AA, b=8.7740 \AA$ and $c=9.4680 \AA$ and is attributed to $\varepsilon-\mathrm{Fe}_{2} \mathrm{O}_{3}$. Analysis shown also the existence of a limited number of peaks which cannot be accurately identified. These peaks could be related to the $\alpha-\mathrm{Fe}_{2} \mathrm{O}_{3}$ and $\gamma-\mathrm{Fe}_{2} \mathrm{O}_{3}$ polymorphs of iron oxide, which might be present in limited quantities, in the nanopowder. At this point it should be noted that the preparation methods of barium ferrite lead to the formation of residual phases which include iron oxide polymorphs $[45,46]$. Summarizing the above discussion, it can be concluded that the recorded magnetic transition cannot be attributed without any doubts to a specific physical mechanism and more research should be conducted in this direction. However, combining XRD spectra with the results from the ZFC and FC curves the recorded magnetic transition it is possible to originate from the $\varepsilon-\mathrm{Fe}_{2} \mathrm{O}_{3}$ polymorph. Finally, to the best of our knowledge, this is the first time where a magnetic transition is observed in ferrite/polymer nanocomposites.

\section{Conclusions}

Two different series of nanocomposites consisting of epoxy resin and $\mathrm{BaFe}_{12} \mathrm{O}_{19}$ or $\mathrm{SrFe}_{12} \mathrm{O}_{19}$ nanoparticles were successfully fabricated and characterized morphologically via scanning electron microscopy and X-ray diffraction spectra. The dielectric response of the nanocomposites was investigated by means of broadband dielectric spectroscopy and their magnetic properties were derived from data obtained by a superconducting quantum interference device. Analysis of the experimental data implies that fine dispersion of the ceramic nanoparticles in the polymer matrix enhances substantially both the magnetic and the dielectric performance of the investigated systems. Although the examined systems exhibit similar behaviour, $\mathrm{SrFe}_{12} \mathrm{O}_{19}$ nanocomposites seems to have the optimum dielectric behaviour in the greater part of the experimental range attaining higher values of $\varepsilon^{\prime}$ than the $\mathrm{BaFe}_{12} \mathrm{O}_{19}$ nanocomposites. Dielectric spectra of all examined systems revealed the presence of three distinct relaxation mechanisms which are attributed to: (i) Interfacial polarization, also known as Maxwell-Wagner-Sillars effect, observed in the low frequency and high temperature region because of the heterogeneity of the systems, (ii) $\alpha$-relaxation, present at intermediate temperatures and frequencies, related to the glass to rubber transition of the polymer matrix and (iii) $\beta$-relaxation due to the re-arrangement of small polar side groups of the macromolecular chain at high frequencies. The magnetic measurements confirmed the ferromagnetic nature of the nanocomposites. The induced magnetic properties increase with the inclusion of hexaferrite nanoparticles. The nanocomposites with $\mathrm{SrFe}_{12} \mathrm{O}_{19}$ nanoparticles exhibit higher values of coercive field, magnetization, magnetic saturation and remanence magnetization. The ZFC/FC tests for the barium ferrite systems revealed an interesting behaviour due to the detected magnetic transition at a characteristic temperature of approximately $109 \mathrm{~K}$.

Author Contributions: For the conceptualization responsible are A.S. and G.C.P., measurements were performed by A.S., S.S., T.S., methodology, validation and data analysis were performed by A.S., S.S., T.S., G.C.P., writing and editing by A.S., S.S., G.C.P.

Funding: This research received no external funding.

Acknowledgments: A.S. wishes to acknowledge the General Secretariat for Research and Technology (GSRT) and the Hellenic Foundation for Research and Innovation (HFRI) for providing a PhD scholarship. (Scholarship Code: 2383).

Conflicts of Interest: The authors declare no conflict of interest.

\section{References}

1. Özgür, Ü.; Alivov, Y.; Morkoç, H. Microwave ferrites, part 1: Fundamental properties. J. Mater. Sci. Mater. Electron. 2009, 20, 789-834. [CrossRef]

2. Warlimont, H. Electronic and magnetic properties of metals and ceramics. Adv. Mater. 1993, 5, 225. [CrossRef]

3. Sharrock, M.P.; Bodnar, R.E. Magnetic materials for recording: An overview with special emphasis on particles (invited). J. Appl. Phys. 1985, 57, 3919-3924. [CrossRef] 
4. Jalli, J.; Hong, Y.; Gee, S.; Bae, S.; Lee, J.; Sur, J.C.; Abo, G.S.; Lyle, A.; Lee, S.; Lee, H.; et al. Magnetic and microwave properteis of Sm-doped SrFe12O19 single crystals. IEEE Trans. Magn. 2008, 44, 2978-2981. [CrossRef]

5. Pullar, R.C. Hexagonal ferrites: A review of the synthesis, properties and applications of hexaferrite ceramics. Prog. Mater. Sci. 2012, 57, 1191-1334. [CrossRef]

6. Gerber, R.; Atkinson, R.; Simsa, Z. Magnetism and magneto-optics of hexaferrite layers. J. Magn. Magn. Mater. 1997, 175, 79-89. [CrossRef]

7. Adam, J.D.; Davis, L.E.; Dionne, G.F.; Schloemann, E.F.; Stitzer, S.N. Ferrite devices and materials. IEEE Trans. Microw. Theory Tech. 2002, 50, 721-737. [CrossRef]

8. Tan, G.; Chen, X. Structure and multiferroic properties of barium hexaferrite ceramics. J. Magn. Magn. Mater. 2013, 327, 87-90. [CrossRef]

9. Kostishyn, V.G.; Panina, L.V.; Timofeev, A.V.; Kozhitov, L.V.; Kovalev, A.N.; Zyuzin, A.K. Dual ferroic properties of hexagonal ferrite ceramics $\mathrm{BaFe}_{12} \mathrm{O}_{19}$ and $\mathrm{SrFe}_{12} \mathrm{O}_{19}$. J. Magn. Magn. Mater. 2016, 400, 327-332. [CrossRef]

10. Kostishin, V.G.; Panina, L.V.; Kozhitov, L.V.; Timofeev, A.V.; Zuzin, A.K.; Kovalev, A.N. Synthesis and multiferroic properties of M-type hexagonal SrFe12O19 ferrite ceramic. J. Surf. Investig. X-ray Synchrotron. Neutron. Tech. 2015, 9, 1152-1155. [CrossRef]

11. Schadler, L.S.; Brinson, L.C.; Sawyer, W.G. Polymer nanocomposites: A small part of the story. JOM 2007, 59, 53-60. [CrossRef]

12. Hanemann, T.; Szabó, D.V. Polymer-Nanoparticle Composites: From Synthesis to Modern Applications. Materials 2010, 3, 3468-3517. [CrossRef]

13. Kanapitsas, A.; Psarras, G.C.; Tsonos, C.; Speliotis, A.; Patsidis, A.C.; Siores, E.; Triantis, D. Magneto-Electric Response and Functionality in Barium Ferrite/Barium Titanate/Epoxy Resin Nanocomposites. J. Adv. Phys. 2016, 5, 1-7. [CrossRef]

14. Psarras, G.C. Editorial corner-A personal view a 'backstage force': Magnetic properties of polymer composites. Express Polym. Lett. 2018, 12, 767. [CrossRef]

15. Psarras, G.C. Conductivity and dielectric characterization of polymer nanocomposites. In Polymer Nanocomposites: Physical Properties and Applications; Tjong, S.C., Mai, Y.W., Eds.; Woodhead Publishing Limited: Oxford, UK, 2010; pp. 31-107. ISBN 978-1-84569-672-6.

16. Sanida, A.; Stavropoulos, S.G.; Speliotis, T.; Psarras, G.C. Development, characterization, energy storage and interface dielectric properties in $\mathrm{SrFe}_{12} \mathrm{O}_{19}$ /epoxy nanocomposites. Polymer 2017, 120, 73-81. [CrossRef]

17. Ding, L.; Liu, L.; Li, P.; Lv, F.; Tong, W.; Zhang, Y. Dielectric properties of graphene-iron oxide/polyimide films with oriented graphene. J. Appl. Polym. Sci. 2016, 133. [CrossRef]

18. Scarlatache, V.-A.; Olariu, M.; Ursache, S.; Ciobanu, R.C.; Pasquale, M. Magnetic and dielectric losses of a nanocomposites polymer matrix reinforced with ferromagnetic powders. In 2012 International Conference and Exposition on Electrical and Power Engineering; IEEE: Piscataway, NJ, USA, 2012; pp. 125-128.

19. Li, Y.; Huang, Y.; Qi, S.; Niu, L.; Zhang, Y.; Wu, Y. Preparation, magnetic and electromagnetic properties of polyaniline/strontium ferrite/multiwalled carbon nanotubes composite. Appl. Surf. Sci. 2012, 258, 3659-3666. [CrossRef]

20. Prabhakaran, T. Hemalatha, Ferroelectric and magnetic studies on unpoled Poly (vinylidine Fluoride)/Fe3O4 magnetoelectric nanocomposite structures. J. Mater. Chem. Phys. 2013, 137, 781-787. [CrossRef]

21. Ouyang, Z.-W.; Chen, E.-C.; Wu, T.-M. Thermal Stability and Magnetic Properties of Polyvinylidene Fluoride/Magnetite Nanocomposites. Materials 2015, 8, 4553-4564. [CrossRef]

22. Tuncer, E.; Sauers, I.; James, D.R.; Ellis, A.R.; Paranthaman, M.P.; Aytuğ, T.; Sathyamurthy, S.; More, K.L.; Li, J.; Goyal, A. Electrical properties of epoxy resin based nano-composites. Nanotechnology 2007, 18, 025703. [CrossRef]

23. Singha, S.; Thomas, M. Dielectric properties of epoxy nanocomposites. IEEE Trans. Dielectr. Electr. Insul. 2008, 15, 12-23. [CrossRef]

24. Bhowmik, R.N.; Vasanthi, V.; Poddar, A. Alloying of $\mathrm{Fe}_{3} \mathrm{O}_{4}$ and $\mathrm{Co}_{3} \mathrm{O}_{4}$ to develop $\mathrm{Co}_{3 x} \mathrm{Fe}_{3(1-x)} \mathrm{O}_{4}$ ferrite with high magnetic squareness, tunable ferromagnetic parameters, and exchange bias. J. Alloys Compd. 2013, 578, 585-594. [CrossRef]

25. Devan, R.S.; Chougule, B.K. Effect of composition on coupled electric, magnetic, and dielectric properties of two phase particulate magnetoelectric composite. J. Appl. Phys. 2007, 101, 014109. [CrossRef] 
26. Pascariu, P.; Airinei, A.; Asandulesa, M.; Rotaru, A. Insights into the optical, magnetic and dielectric properties of some novel polysulfone/ $\mathrm{NiFe}_{2} \mathrm{O}_{4}$ composite materials. Polym. Int. 2018, 67, 1313-1324. [CrossRef]

27. Cornell, R.M.; Schwertmann, U. The Iron Oxides; Wiley-VCH Verlag GmbH \& Co. KGaA: Weinheim, Germany, 2003. [CrossRef]

28. Ioannou, G.; Patsidis, A.; Psarras, G.C. Dielectric and functional properties of polymer matrix $/ \mathrm{ZnO} / \mathrm{BaTiO}_{3}$ hybrid composites. Compos. Part A Appl. Sci. Manuf. 2011, 42, 104-110. [CrossRef]

29. Vassilikou-Dova, A.; Kalogeras, I.M. Dielectric Analysis (DEA). In Thermal Analysis of Polymers; Menczel, J.D., Prime, R.B., Eds.; John Wiley \& Sons, Inc.: Hoboken, NJ, USA, 2009; pp. 497-613.

30. Mathioudakis, G.N.; Patsidis, A.C.; Psarras, G.C. Dynamic electrical thermal analysis on zinc oxide/epoxy resin nanodielectrics. J. Therm. Anal. Calorim. 2014, 116, 27-33. [CrossRef]

31. Vryonis, O.; Anastassopoulos, D.L.; Vradis, A.A.; Psarras, G.C. Dielectric response and molecular dynamics in epoxy-BaSrTiO 3 nanocomposites: Effect of nanofiller loading. Polymer 2016, 95, 82-90. [CrossRef]

32. Liu, Q.; Banerjee, S.K.; Jackson, M.J.; Chen, F.; Pan, Y.; Zhu, R. Determining the climatic boundary between the Chinese loess and palaeosol: Evidence from aeolian coarse-grained magnetite. Geophys. J. Int. 2004, 156, 267-274. [CrossRef]

33. Miyahara, Y. Impurity Effects on the Transition Temperature of Magnetite. J. Phys. Soc. Jpn. 1972, 32, 629-634. [CrossRef]

34. Özdemir, Ö.; Dunlop, D.J.; Moskowitz, B.M. The effect of oxidation on the Verwey transition in magnetite. Geophys. Res. Lett. 1993, 20, 1671-1674. [CrossRef]

35. Walz, F.; Rivas, J.; Martínez, D.; Kronmüller, H. Influence of Ba content on the magnetic after-effect spectra in barium ferrites. Phys. Status Solidi 1994, 143, 137-148. [CrossRef]

36. Walz, F.; Torres, L.; de Francisco, C.; Iñiguez, J.; Kronmüller, H. Analysis of Magnetic After-Effect Spectra in Zinc Ferrites. Phys. Status Solidi 1997, 163, 233-246. [CrossRef]

37. Walz, F. The Verwey transition-A topical review. J. Phys. Condens. Matter 2002, 14, R285-R340. [CrossRef]

38. Sorescu, M.; Brand, R.A.; Mihaila-Tarabasanu, D.; Diamandescu, L. The crucial role of particle morphology in the magnetic properties of haematite. J. Appl. Phys. 1999, 85, 5546-5548. [CrossRef]

39. Zhao, Y.; Dunnill, C.W.; Zhu, Y.; Gregory, D.H.; Kockenberger, W.; Li, Y.; Hu, W.; Ahmad, I.; McCartney, D.G. Low-temperature magnetic properties of hematite nanorods. Chem. Mater. 2007, 19, 916-921. [CrossRef]

40. Díaz-Guerra, C.; Pérez, L.; Piqueras, J.; Chioncel, M.F. Magnetic transitions in $\alpha-\mathrm{Fe}_{2} \mathrm{O}_{3}$ nanowires. J. Appl. Phys. 2009, 106. [CrossRef]

41. Tuček, J.; Zbořil, R.; Namai, A.; Ohkoshi, S.I. $\varepsilon-\mathrm{Fe}_{2} \mathrm{O}_{3}$ : An advanced nanomaterial exhibiting giant coercive field, millimeter-wave ferromagnetic resonance, and magnetoelectric coupling. Chem. Mater. 2010, 22, 6483-6505. [CrossRef]

42. MacHala, L.; Tuček, J.; Zbořil, R. Polymorphous transformations of nanometric iron(III) oxide: A review. Chem. Mater. 2011, 23, 3255-3272. [CrossRef]

43. Dubrovskiy, A.A.; Balaev, D.A.; Shaykhutdinov, K.A.; Bayukov, O.A.; Pletnev, O.N.; Yakushkin, S.S.; Bukhtiyarova, G.A.; Martyanov, O.N. Size effects in the magnetic properties of $\varepsilon-\mathrm{Fe}_{2} \mathrm{O}_{3}$ nanoparticles. J. Appl. Phys. 2015, 118, 213901. [CrossRef]

44. Xu, K.; Feng, J.S.; Liu, Z.P.; Xiang, H. Origin of Ferrimagnetism and Ferroelectricity in Room-Temperature Multiferroic $\epsilon-\mathrm{Fe}_{2} \mathrm{O}_{3}$. J. Phys. Rev. Appl. 2018, 9, 044011. [CrossRef]

45. Pillai, V.; Kumar, P.; Multani, M.S.; Shah, D.O. Structure and magnetic properties of nanoparticles of barium ferrite synthesized using microemulsion processing. Colloids Surf. A Physicochem. Eng. Asp. 1993, 80, 69-75. [CrossRef]

46. González-Carreño, T.; Morales, M.; Serna, C. Barium ferrite nanoparticles prepared directly by aerosol pyrolysis. Mater. Lett. 2000, 43, 97-101. [CrossRef]

(C) 2018 by the authors. Licensee MDPI, Basel, Switzerland. This article is an open access article distributed under the terms and conditions of the Creative Commons Attribution (CC BY) license (http:/ / creativecommons.org/licenses/by/4.0/). 